\title{
I nformation availability for the families of stroke patients at an emergency department: A training intervention study
}

\author{
Pirjo Virtanen ${ }^{1}$, Eija Paavilainen ${ }^{2,} 4$, Pirjo Aalto ${ }^{3}$, Mika Helminen ${ }^{2,3}$, Päivi Åstedt-Kurki², 3 \\ 1. Production area for specialized medical care, City of Tampere, Finland. 2. School of Health Sciences, University of \\ Tampere, Finland. 3. Science Centre, Pirkanmaa Hospital District, Finland. 4. Etelä-Pohjanmaa Hospital District, Finland.
}

Correspondence: Pirjo Virtanen. Address: P.O. Box 131, 33101, Tampere, Finland. Email: pirjo.m.virtanen@tampere.fi

Received: July 4, 2013

DOI : $10.5430 /$ cns.v1n4p56
Accepted: August 28, 2013

URL: http://dx.doi.org/10.5430/cns.v1n4p56

\section{Abstract}

In this study, the information availability for the families of stroke patients at an emergency department (ED) is described and how a training intervention for the staff can change this is studied. The material for the study was collected by using a survey questionnaire given to stroke patients and their families in two university hospital EDs from 2006-2008. The first set of material $(n=85)$ was collected before the training intervention and the second set $(n=72)$ after the intervention.

The first survey examined stroke patients' and their families' experience of the information availability at the two EDs. After the first survey, a training intervention was conducted where one of the two EDs functioned as the intervention ED and the other one functioned as the control ED. After this, a new survey was carried out for the stroke patients and their family members at both the intervention ED and the control ED. This article discusses the family members' experiences of information availability before and after the training intervention.

In the family members' experience, the information availability was best realized regarding keeping them informed about issues and tests, staff treatment and issues relating to the information availability for the family member the patient informed. The worst realized components of information availability were related to discussing symptoms, the patient instructions received and informing about medication and IV therapy.

In the training the staff of the intervention ED received information on background factors, risk factors and symptoms of strokes and different treatment forms. The training also discussed the role of the family member as the patient's supporter when healing and/or coping with the disease. In addition to the training, the intervention ED adopted new written instructions designed for stroke patients and their family.

According to the results, the effect of the educational intervention was not statistically significant when comparing the intervention emergency department and the control emergency department, although the information availability was seen to have improved for each component when analysed separately. The interaction effect term is positive in each of the nine components of information availability, which indicates that there has been more positive development at the intervention emergency department than at the control emergency department.

Among the background factors, waiting time at the emergency department, waiting time before a doctor arrived to examine the patient and whether the doctor arrived soon enough were connected to the information availability experienced by stroke patients' family members. 
The results support the idea that an intervention can have a positive effect on the information availability as perceived by the families of stroke patients.

\section{Key words}

Information availability, Stroke patient, Family, Emergency department, Intervention

\section{I ntroduction}

There are few national or international intervention studies on the information availability for the families of stroke patients. The challenges in intervention studies are the changing operational environment and evaluating which factors affect the end result, and to what extent ${ }^{[1]}$.

The structural changes in Finnish health care and the increased emphasis on evidence-based practices require continuous evaluation of health care operations and additional training. Training can be used to support a client-centric focus, taking ethical viewpoints into account and to support a patient's right to receive the best and most current treatment. Training is also seen as an important and fairly efficient method to develop evidence-based practices ${ }^{[2,3]}$.

Hospitalization periods have become shorter, treatment is fast-paced and treatment is increasingly given in policlinics. The information availability for patients and their families is emphasized in the patient's overall care. Good information availability has positive effects on treatment success, how information related to the illness is understood, on self-care and treatment commitment, and on coping with everyday life. The treatment responsibility is quickly transferred to patients and their families when the patient is dispatched from the hospital ${ }^{[4,5]}$. While the families receive the treatment responsibility, they do not receive enough attention, information and support from the health care personnel ${ }^{[3,5,6]}$.

Involving a stroke patient's family in the treatment helps the patient to cope with the illness ${ }^{[7]}$. It is important for the family to receive enough information on what the treatment requires from them regarding skills and responsibilities ${ }^{[8]}$. Often the follow-up treatment of a stroke patient relies on the information, knowledge and support of the family ${ }^{[5,6,9]}$. In acute emergency department (hereafter 'ED') situations, the family's knowledge and expertise are emphasized when instructing and guiding the patient. The patients and their families may feel that they do not receive enough information for participation in treatment planning. By examining the information availability from the stroke patient's family's viewpoint, we can gain a more holistic view of the information availability for stroke patients and their families in EDs.

Stroke as a term refers to cerebrovascular diseases, cerebral venous diseases or both, which cause transient or permanent neurological symptoms. Strokes are the third most expensive disease group in Finland due to long periods of hospitalization and inability to work. The majority of patients are directed to EDs.

In addition to physical changes, a stroke can cause different kinds of cognitive and emotional changes that hinder the patient from adapting to their new life situation. The patients experience difficulty moving, have fewer social contacts and a worse quality of life, and have increased rates of depression ${ }^{[10]} .40 \%$ of the patients require long-term rehabilitation treatment and the effectiveness of rehabilitation is the highest during the first 2-3 weeks. Three months after the stroke, approximately $50 \%-70 \%$ of the patients have recovered enough to be independent in their daily activities, while $15 \%-30 \%$ remain permanently physically challenged and approximately $20 \%$ require institutional care ${ }^{[4,10]}$.

\section{Materials and methods}

\subsection{Theoretical starting points}

When a family member suddenly falls ill, the functionality, assumed roles and everyday routines of the family are disturbed. Values also change: what used to be important loses its significance ${ }^{[5,11]}$. Anger, guilt, helplessness and 
powerlessness are typical emotions in an acute onset of a disease. The disease causes stress for family members, evident in a lack of appetite, sleeping difficulties and irritability ${ }^{[4,6,11,12]}$.

In this study, the term "family" or "family member" includes close friends. The patients define who their family members are ${ }^{[6,12]}$. The families' stress control and problem solving skills need to be strengthened by giving them information ${ }^{[24]}$ as their support has an impact on how the patient adapts and copes ${ }^{[6,11,12]}$. The families need information on strokes - the physical, cognitive, emotional and behavioural changes they cause - and personal guidance ${ }^{[3,4,20]}$. They also expect to be given justifications for the selected course of action ${ }^{[5,8]}$.

The patient is often accompanied either by a family member, friend or legal guardian ${ }^{[14]}$. The patients and their families emphasize the following aspects of information availability: keeping them up to date on treatment progression, giving information at intervals during the treatment, and giving information on the urgency of treatment and how this determines the waiting time ${ }^{[6,15]}$. According to earlier studies ${ }^{[6,14,15]}$ a long waiting time has a negative impact on the patient's information availability.

Families would like written treatment instructions for home care to support their memory ${ }^{[6,8,16,17]}$. They want information on the medication and to attend the patient guidance session to treat the patient after they return home ${ }^{[6]}$. The family's presence during treatment increases the patient's feeling of safety and strengthens trust in the personnel ${ }^{[8]}$, especially when the patient is elderly ${ }^{[6,18,19]}$.

In this study, the family's information availability consists of the following nine components: staff treatment, discussing tests, medication and IV therapy, discussing the disease, discussing symptoms, patient instructions, information on follow-up treatment, and informing about issues and the family's information availability.

Based on existing research knowledge, not enough attention has been paid to the information availability for the patient's

family ${ }^{[6,16,19]}$. More research is needed to improve this situation ${ }^{[6,20]}$. For this reason, an intervention study was conducted, described in this article.

\subsection{The purpose of the study and the research questions}

The purpose of the study is to describe the information availability for a stroke patient's family at an ED and to find out whether a staff training intervention has changed the information availability.

The research questions are the following:

- How does the patient's family experience information availability?

- Which of the background factors of the patient's family affect their information availability?

- Has the staff training intervention changed the way the patient's family experiences the information availability?

\subsection{Data and methods}

\subsubsection{Target group}

The target group of the study were stroke patient's families in the EDs of two university hospitals. Altogether 1,000 stroke patients were selected from patient history data (dg I63 and G45) during two different measurement stages; before ( $\mathrm{n}=500)$ and after $(n=500)$ the training intervention. Patients were chosen who had had their first stroke and been treated at an ED by the last day of the month. A structured questionnaire about information availability was sent to the patients and their families, accompanied by a covering letter that explained the purpose of the study, a consent form and a return envelope. 
After the first survey, a training intervention was conducted where one of the emergency departments functioned as the intervention ED and the other one functioned as the control ED. After this, a new survey was carried out for the stroke patients and their family members at both the intervention ED and the control ED. This article deals with the family members' experiences of information availability before and after the training intervention.

This paper is based on the responses from both hospitals, primarily on those of the 72 family members who responded during the second stage (17.10.2007 - 20.7.2008, $n=32+40=72)$. Possible changes due to the intervention are studied by comparison to the 85 family members from the first stage $(1.10 .2006-14.6 .2007, n=36+49=85)$. The results of the first measurement stage before the training intervention have been reported in a previously published article ${ }^{[6]}$.

\subsubsection{Questionnaire}

The data collection method was a structured questionnaire that included one open question. Initially, the aim was to modify an existing, tested questionnaire for this study but, as such a questionnaire was not found, a questionnaire was developed with an expert group, utilizing earlier measures ${ }^{[15,21,22]}$ theory on information availability, guidance and instructions ${ }^{[7,14]}$ and the author's work experience.

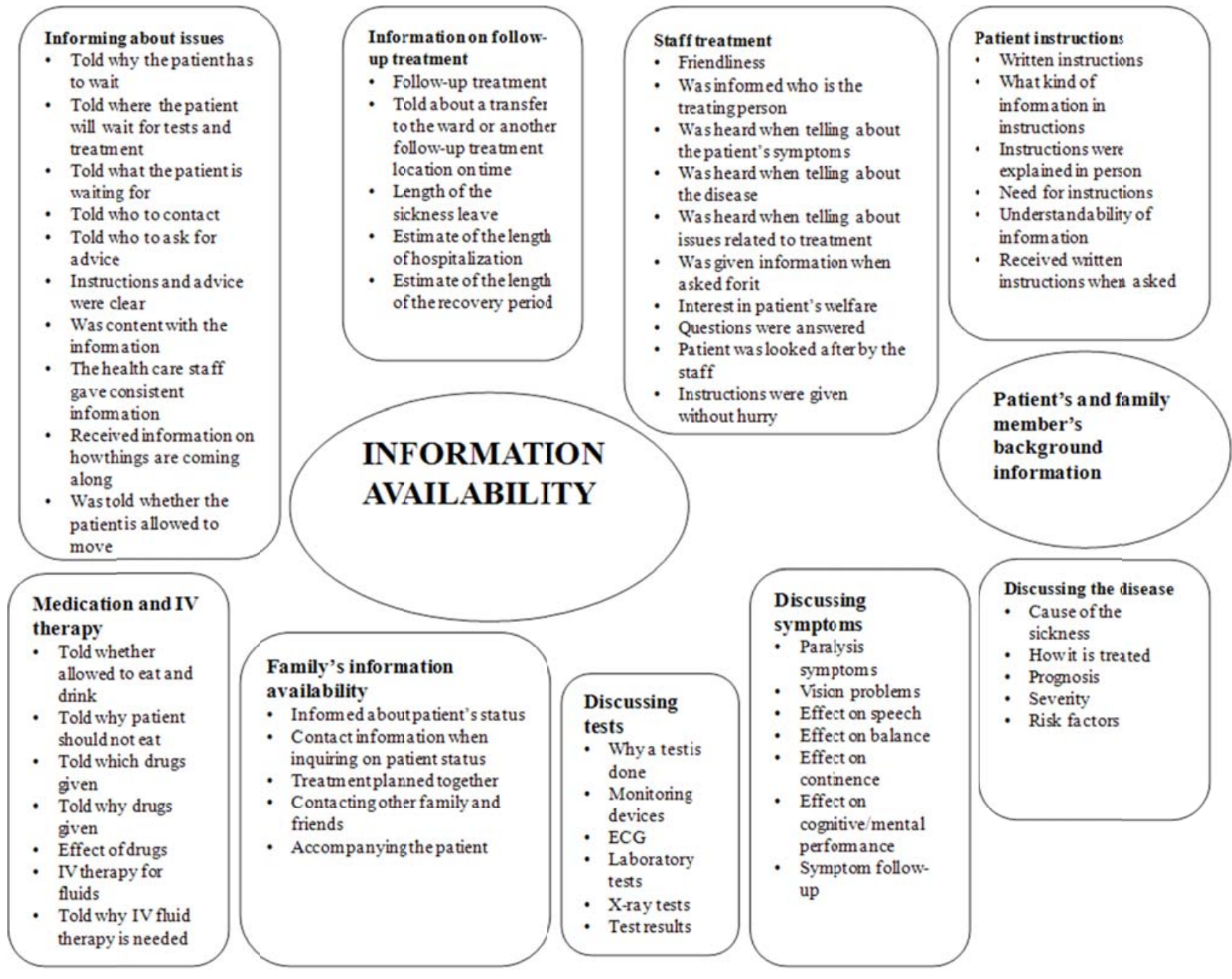

Figure 1. Components measuring information availability 
The questionnaire included 12 background questions and components measuring information availability: staff treatment (10 questions), discussing tests (6), medication and IV therapy (7), discussing the disease (5), discussing symptoms (7), patient instructions (6), information on follow-up treatment (5), informing about issues (10) and family's information availability (5). The separate questions were evaluated on a four-level Likert scale ( 4 = totally agree, $3=$ partly agree, $2=$ partly disagree, 1 = totally disagree and, additionally, $0=$ the issue did not concern me). The questions were formulated so that responding ' 4 ' indicated satisfaction and ' 1 ' indicated dissatisfaction. The mean values of questions in each component were used to describe the information availability(see Figure 1).

The background factors determined the socio-demographic factors of the patient's family, when they arrived at the ED, their relationship to the patient and the location of the follow-up treatment. Other questions about background factors were whether this was the patient's first admittance to the ED (yes/no/cannot say), the waiting time (eight different subclasses; no waiting time, $<30$ minutes, ... , > 12 hours, whether the physician arrived quickly enough (yes/no/cannot say), and how important the family thought their presence at the ED was (very important/fairly important/not very important/not at all important). The open question was used to find out what information they lacked. The questionnaire was returned anonymously ${ }^{[9]}$.

The expert group that helped with the questionnaire consisted of a neurologist, a statistician, three nursing science researchers and three nurses working at an ED $(n=8)$, and they evaluated whether the content corresponded to the background theory. A pilot test was conducted at the ED of a university hospital that treated neurological patients with the patients' family members $(n=10)$ as the respondents. Based on these responses, no changes were needed in the questionnaire.

Approvals were acquired for the study as required by the health care districts. The mailing of the questionnaires, introduction and discussion of the study, and data collection and analysis were conducted according to the guidelines for research ethics. The informants' identities were not connected to the questionnaires at any point ${ }^{[9,12]}$.

Internal consistency was assessed with Cronbach's alpha ${ }^{[9,12]}$. Cronbach's alpha was located within the range of 0.76-0.98 per component before the intervention and within the range of 0.78-0.97 after the intervention. All in all, the consistency was proven to be good.

The loss of study subjects in the second stage in relation to the whole data set (55\%) can cause bias in the results. One reason for this is that it was impossible to predetermine how many patients' families accompanied them to the ED and how many would respond to the questionnaire. The patient data was a starting point for determining the theoretical maximum size of the family data set: 1,000 stroke patients were retrieved from databases, based on diagnostic information and predetermined criteria ${ }^{[12]}$. The sample size is typical for comparable questionnaires ${ }^{[9,12]}$. However, based on the results of the patient data analysis ${ }^{[6]}$, only $35 \%$ arrived at the ED with family. Therefore, the approximated maximum number of families should be 350 (1000 patients $\left.{ }^{*} 0.35=350\right)$.

The time and duration of the study were determined by practicality, and the number of the patients and their family members could not be increased. Data collection lasted approximately six months in both stages. Loss analysis could not be carried out due to the lack of background information for those who did not respond. The range in the number of responses for both stages was 48-97. On average, $20 \%$ of the questions got no response.

\subsubsection{The content of the training intervention}

As part of an intervention strategy, a training intervention was developed for the hospital's health care staff, and written instructions were devised for patients. The contents of the training and the patient instructions were devised by a neurologist, nurses caring for neurological patients and the researcher. In addition, a family member of a stroke patient was asked to evaluate the written instructions. The intervention was designed partly based on pilot measurements and partly based on earlier research. 
The training was carried out in autumn 2007 after the first data collection stage. The intervention included both training for the health care staff at the intervention ED and the designing of written instructions. Altogether 85 members of health care personnel (hospital nurses, practical nurses, department secretaries, clinic assistants, and physicians) participated, and the training was repeated until the whole ED personnel had been trained. One training session involved two 45-minute parts. The first part discussed the medical diagnostics of a stroke patient, the treatment and diversity of symptoms. The second part discussed monitoring the patient's condition and symptoms, keeping them informed about tests, treatment and related issues, patient instructions and follow-up treatment. Additionally, the training discussed the importance of the family's presence in the patient's care and treatment. The aim was to make the training intervention as interactive as possible by choosing people already familiar to the health care staff as trainers. The chosen trainers also worked at the intervention emergency clinic in question. One of them was a neurology specialist and the other one a head nurse. The trainers challenged the health care staff to discuss issues and present questions during the training. In addition, the training discussed example cases to keep the staff interested throughout the training.

The written instructions were directed at stroke patients and their families. The instructions were kept short because according to earlier studies ${ }^{[5,26]}$, patients and families are not able to read and understand long and verbose instructions. The instructions discussed the symptoms, risk factors and treatment of strokes. They also included instructions for how the patient should act if they experience sudden stroke symptoms. At the end of the instructions, there was contact information for places where to get additional information on strokes. The contact information included the phone numbers, email addresses and street addresses of the hospital and the patient association. The new written instructions were adopted into use at the intervention ED after they were given training and guidance for adopting them during the intervention training course. The intervention ED had not had similar instructions in use before. The nurses at the intervention clinic were instructed to always give written instructions to the patient and their family.

\subsubsection{Data analysis}

Average values were calculated from the responses to the different components of information availability. The analysis only included those who had responded to at least $80 \%$ of the questions and omitted "cannot say" responses. The few short responses to the open question are illustrated with direct quotes.

Responses to the open question were analyzed with content analysis. Those open responses that were in keeping with responses received through statistical methods have been included in the article as descriptive examples.

The statistical methods used were frequency and percentage distributions, Mann-Whitney and Kruskal-Wallis tests, Spearman correlation and linear regression. In the regression model, the average value of the components was explained with the following variables: sex, waiting time (interpreted as continuous), higher education (yes/no), previous visits to the emergency ward (yes/no), marital status (married/ single/ divorced/ widow(er)), age (under 65/65 or over), time of measurement (before or after the training intervention) and test hospital or control hospital. An interaction effect term to measure the intervention's effectiveness was built by multiplying the two last variables mentioned above with each other to examine their interaction. Thus, changes in the test hospital are examined in relation to changes in the control hospital. The threshold for statistical significance was a p value of 0.05 . The data were analysed with SPSS (SPSS for Windows, version 17.0).

\section{Results and discussion}

First, the results after the training intervention are presented for both hospitals regarding the families' experiences of information availability, and factors related to them are examined. Afterwards, the results of the intervention are presented. 
Among patients who responded, 35 \% (125/356) arrived at the ED with family. If we assume that the same percentage applies to the patient data as a whole $(n=1000)$, then in theory there would have been 350 accompanying family members, and the response rate for the whole data set would be $45 \%$ (157/350).

\subsection{The background information of the families}

After the training intervention, 72 family members of stroke patients participated in the study. The majority of the respondents (53\%) were at least 60 years old. $78 \%$ of them were women and $22 \%$ were men. The majority were married or living with someone (81\%) and polytechnic education (old system) was their highest level of education (32\%). Table 1 shows the results before and after the training intervention (see Table 1).

Table 1. Background information on the patients' families before and after the training intervention

\begin{tabular}{|c|c|c|c|c|}
\hline \multirow{2}{*}{ Background factors } & \multicolumn{2}{|c|}{ before $(n=85)$} & \multicolumn{2}{|c|}{ after $(n=72)$} \\
\hline & $\mathbf{n}$ & $\%$ & $\mathbf{n}$ & $\%$ \\
\hline \multicolumn{5}{|l|}{ Age } \\
\hline 49 or under & 17 & 20 & 21 & 29 \\
\hline $50-59$ & 28 & 33 & 13 & 18 \\
\hline $60-69$ & 21 & 25 & 25 & 35 \\
\hline $70-79$ & 17 & 20 & 11 & 15 \\
\hline 80 or over & 2 & 2 & 2 & 3 \\
\hline \multicolumn{5}{|l|}{ Sex } \\
\hline Female & 62 & 73 & 56 & 78 \\
\hline Male & 23 & 27 & 16 & 22 \\
\hline \multicolumn{5}{|l|}{ Marital status } \\
\hline Unmarried & 5 & 6 & 8 & 11 \\
\hline Married / living together & 70 & 82 & 58 & 81 \\
\hline Divorced & 4 & 5 & 5 & 7 \\
\hline Widow/widower & 6 & 7 & 1 & 1 \\
\hline \multicolumn{5}{|l|}{ Educational level } \\
\hline $\begin{array}{l}\text { Common school/elementary } \\
\text { school/middle school }\end{array}$ & 30 & 35 & 20 & 28 \\
\hline Vocational education & 20 & 24 & 17 & 24 \\
\hline Polytechnic (old system) & 20 & 24 & 23 & 32 \\
\hline Polytechnic (new system) & 2 & 2 & 3 & 4 \\
\hline University & 11 & 13 & 8 & 11 \\
\hline Information missing & 2 & 2 & 1 & 1 \\
\hline
\end{tabular}

\subsection{I nformation availability as experienced by the patient's family}

The families felt that the following components of information availability were best realized: keeping them informed (e.g. why and where the patient I am accompanying is waiting; $\mathrm{n}=57$, mean 2.83), informing about tests (e.g. why and which test is going to be done; $n=57$, mean 2.67), staff treatment (e.g. the patient was treated in a friendly way, the staff introduced themselves and listened; $\mathrm{n}=57$, mean 3.22), and informing about issues and informing the family (e.g. informing about the patient's condition, treatment was planned together; $n=47$, mean 2.72). The worst realized 
components were: discussing the symptoms (e.g. the possibility of paralysis, vision impairment and speech impairment; $n$ $=50$, mean 1.86), the patient instructions received $(\mathrm{n}=29$, mean 1.91), and informing about medication and IV therapy ( $\mathrm{n}$ $=42$, mean 2.34) (see Table 2).

Table 2. The experience of patients' families $(n=72)$ of how the different components of information availability were realized at the emergency department after the training intervention

\begin{tabular}{lll}
\hline Components of information availability & Mean & $\mathbf{n}$ \\
\hline Informing about issues & 2.83 & 57 \\
Discussing tests & 2.67 & 57 \\
Informing about medication and IV therapy & 2.34 & 42 \\
Staff treatment & 3.22 & 57 \\
Discussing the disease & 2.57 & 58 \\
Discussing the symptoms & 1.86 & 50 \\
Patient instructions & 1.91 & 29 \\
Family's information availability & 2.72 & 47 \\
Information on follow-up treatment & 2.52 & 54 \\
\hline
\end{tabular}

Note. Scale 1-4: 4 = totally agree, 3 = partly agree, 2 = partly disagree, $1=$ totally disagree

In response to the open question, one family described the staff treatment and informing about tests as follows:

After the computed tomography, the neurologist said that the stroke was the reason for the patient's incoherence and sudden memory loss. The next morning the patient was sent home and monitored at home for 2-3 weeks.

Regarding the component of informing about issues and informing the family, one respondent said:

The waiting time stretched out quite long and no one would tell me what was going on or why we were waiting. I would have wanted to be updated a bit more often. I would like to know what the disease was, what caused it, how likely it was to recur and how it could be prevented. I did not meet the treating physician at any point.

\subsection{Factors related to information availability}

No statistically significant differences emerged when looking for a connection between how information availability was realized for the patient's family and their marital status, age and whether or not patients had had a previous visit to the ED. However, families who felt that the physician had not arrived to examine the patient quickly enough also felt that information availability was badly realized for most components (see Table 3). Men felt that the component of discussing symptoms was better realized than women did (the mean for the whole component was 1.86; it was 1.67 for women and 2.51 for men, with a Mann-Whitney p value $=0.018$ for gender differences).

The correlation analysis showed that the longer the patients' families have to wait at the ED, the worse the information availability is for them. Nevertheless, the correlations were statistically significant only for some components, varying between -0.09 and -0.52 among them.

\subsection{Changes in the information availability}

During 2006-2007 and 2007-2008, 157 family members of stroke patients participated in the study and their responses were included in the intervention part. With regression analysis, changes in information availability were examined between these periods. 
The intervention did not have a statistically significant effect regarding the changes in the components' mean values. However, the interaction effect term is positive in the models for each component, indicating that the intervention might have been useful. In addition, despite the non-significance, some of the models indicate quite large changes in information availability. For example,

for the component of discussing and informing about tests, the value of the interaction effect term, i.e. the change in the test hospital in relation to the control hospital, was 0.94 units in the mean value of the component $(\mathrm{p}=0.056)$. These two findings support the idea that the intervention had some indicative effect on information availability. When examining the significance of the interaction effect term by replacing the waiting time factor with the question "Did the physician arrive quickly enough?”, the results were somewhat strengthened.

Table 3. Comparison of experience on patients' families $(n=72)$ information availability between yes and no -answers to question "whether the physician arrived quickly enough to examine the patient"

\begin{tabular}{llllllll}
\hline \multirow{2}{*}{ Components of information availability } & \multicolumn{2}{l}{ Yes } & & & No & \multicolumn{2}{c}{$\begin{array}{l}\text { Mann-Whitney } \boldsymbol{p} \\
\text { value }\end{array}$} \\
\cline { 2 - 3 } & Mean & $\mathbf{n}$ & & Mean & $\mathbf{n}$ & \\
\hline Informing about issues & 3.40 & 31 & & 2.20 & 14 & 0.000 \\
Discussing tests & 3.10 & 31 & & 2.27 & 14 & 0.059 \\
Informing on medication and IV therapy & 2.88 & 24 & & 1.67 & 7 & 0.014 \\
Staff treatment & 3.56 & 33 & & 2.88 & 14 & 0.008 \\
Discussing the disease & 3.05 & 32 & & 2.19 & 14 & 0.082 \\
Discussing the symptoms & 2.23 & 27 & & 1.56 & 13 & 0.085 \\
Patient instructions & 2.13 & 19 & & 1.38 & 6 & 0.157 \\
Family's information availability & 3.03 & 28 & & 2.24 & 11 & 0.036 \\
Information on follow-up treatment & 3.04 & 31 & & 2.01 & 12 & 0.002 \\
\hline
\end{tabular}

Note. (Scale 1-4: 4 = totally agree, 3 = partly agree, 2 = partly disagree, 1 = totally disagree)

\section{Discussion}

\subsection{Analysis of the research results and improving the information availability}

The families felt that the best realized components of information availability were: informing about issues, discussing tests, staff treatment and the family's information availability. The worst realized components of information availability were: discussing symptoms, patient instructions, and informing about medication and IV therapy. The results agree with earlier studies ${ }^{[4,6,19]}$, where the patient's family was insufficiently involved in guidance sessions and insufficiently informed about the disease.

The families' background factors that affected their information availability were: the waiting time, previous hospital experience and whether the respondent felt that the physician arrived quickly enough. Families felt that they needed information as soon as possible after arriving at the ED. The sooner they received information from the examining physician, the better the information availability was for them for each component. This result agrees with earlier research results ${ }^{[3,6,24]}$. At the ED, the family is worried about the patient's condition, and this is reflected in the significance of the waiting time. 
The families need more information on the progression of treatment and they need to be regularly updated ${ }^{[5,6]}$. In response to the open question, families described having been forgotten in the waiting room and not being kept informed of the patient's condition or whereabouts. Keeping the family informed in general and informing about the progression of the treatment emerge as factors that promote the family's control of the situation and decrease their uncertainty. It is easier to endure waiting once one knows what one is waiting for and why ${ }^{[5,20]}$. The importance of informing the family has also been found in earlier studies ${ }^{[6,23]}$.

The presence of family in the patient's treatment situation is important, and families want information on the possibility of participation ${ }^{[5,6]}$. In addition, they need information on how they can contact others outside the hospital whilst waiting and the patient whilst outside the hospital ${ }^{[3,14,24]}$. The family's need to maintain contact with the patient from outside the hospital during treatment was also identified in this study. The families made suggestions for improvements to information availability when calling the hospital.

Technical competence and the professional skills of health care workers are factors that are emphasized in the nursing work at the ED. Especially with elder patients, information about medication, IV therapy and nutrition are seen as important ${ }^{[3,14]}$, but also the significance of having a family member present is emphasized ${ }^{[6]}$ in the responses. The nursing work at the ED should be developed to be more customer and family-based and away from the current task-centered practice of nursing.

Based on the results, the training intervention has affected information availability because there are signs of it having improved afterwards. This result supports the idea that a training intervention has a positive effect on the information availability for the families. The result agrees with earlier studies ${ }^{[3,19]}$, where interventions have been either effective or partially effective.

In a stroke patient's treatment, the emphasis and aim of the development of practices have been in improving diagnostics and developing different kinds of tests and treatment methods. Developing the information availability for the patients and their family has received less attention. Supporting information availability and developing guidance methods affect how patients adapt to their new life situation and how their families are able to support them ${ }^{[6,17]}$. In order to shorten hospitalization periods and increase the pace of treatments, it is important to better utilize the resources of the patients' families ${ }^{[25]}$.

The training intervention used in this study involved two 45-minute sessions and the training was aimed at the health care staff of the intervention ED. In addition, written instructions were designed and written, aimed at stroke patients and their families. No statistically significant change was achieved with the training intervention, but it had a positive influence on all nine components of information availability. In the future, more research is needed on the effect of training interventions. Especially the effects of a systematic long-term training intervention should be studied because in order to change established practices permanently and adopt new practices, we need more efficient interventions that are based on long-term evidence.

The aim was to make the training intervention an interactive event where the trainers challenged the health care staff to discuss issues and present questions. Additionally the training included case examples to keep the staff interested through the whole training ${ }^{[2,17]}$. The training intervention could have been made even more interactive by arranging group tasks and exercises, so that each trainee would have been more motivated and able to participate more interactively.

The results suggest that the implemented intervention strategy should have included a long-term training for the health care staff, and the adoption of the written instructions for patients and family should have been planned and implemented more systematically. In the future it is important to invest in more effective and long-term training interventions if the aim is to achieve statistically significant changes in nursing practices. 
The results support the idea that training interventions are needed to develop the information availability, that the patient's families should be systematically involved, and that close collaboration is needed with neurological experts. Health care personnel are unsure of their role when they instruct and inform families ${ }^{[6,17]}$. The functionality of the patients' treatment chains should be improved and the roles of the patient's family and health care personnel should be clarified as part of patient treatment and development of information availability.

\subsection{Evaluation of the study's reliability}

When evaluating the effectiveness of the intervention, it is important to consider whether the results were caused by the intervention or due to other factors. In this study, the choice of the test and control hospitals was affected by the number of their stroke patients, their location, and logistical concerns. The aim was to conduct the study when there was no other broad and systematic training going on in either hospital.

The study answered the research questions. Unfortunately the fairly small size of the data set limited the use of multifactor methods ${ }^{[9]}$. The results are indicative, as no sufficient statistical significance was reached for the intervention models. The value of the results lies in the description of a subject that has received little research and in defining the concept of information availability. The results can be applied and used in the operational environment of EDs.

The reliability of the study is weakened by the questionnaire including some "the issue did not concern me" responses. In addition, the data were gathered only from the EDs of two university hospitals, and the results cannot be directly generalized. Although the patients' families were asked to evaluate information availability at the ED, it is possible that their experience has been influenced by information received at the ward, and this may also affect the reliability.

The reliability of the study was increased, however, by the fact that the data were gathered specifically for this study and that the researcher was able to influence the collection of data and the monitoring of the collection process throughout the whole research process ${ }^{[26]}$.

\section{Conclusions}

The study indicates that the training intervention had some positive effect on how stroke patients' families experienced information availability.

Based on the results, the following conclusions can be made:

1) The waiting time at the ED is connected to how information availability has been experienced.

When developing ED practices, the significance of waiting times must be taken into account also from the point of view of the family, as a long waiting time may result in bad information availability for the family.

2) More attention needs to be paid to involving stroke patients' families in guidance sessions and to giving information about the disease to the family. The information availability for the family needs to be supported by written patient instructions.

3) In order to improve information availability for the patients' families, different guidance and instruction methods need to be utilized. The existing telephone instruction practices need to be improved at EDs, and the information availability for the family should be ensured on the phone as well.

4) When developing information availability from the point of view of the patient and the family, it is necessary to involve both in the planning of staff training. 
5) More systematic and long-term intervention studies are needed in order to change and develop nursing practices. Changing established practices and adopting new ones requires more efficient interventions based on long-term evidence.

6) Nursing work at emergency departments should be developed to be more customer and family-based, away from the current task-centered practices of nursing work.

\section{Declarations of interest}

The authors declared no conflict of interest.

\section{References}

[1] Campbell NC, Murray E., Darbyshire J, Emery J, Farmer A, Griffiths F, Guthrie B, Lester H, Wilson P, Kinmonth AL. Designing end evaluating complex interventions to improve health care. British Medical Journal. 2007; 334(7591): 455-459. http://dx.doi.org/10.1136/bmj.39108.379965.BE

[2] McAllister M, Osborne SR. Teaching and learning practice development for change. Journal of Continuing Education in Nursing 2006; 37(4): 154-159. PMid:16892666

[3] Yonaty S-A., Kitchie S. The Educational Needs Of Newly Diagnosed Stroke Patients. American Association of Neuroscience Nurses. 2012; 44 (5): E1-E9. http://dx.doi.org/10.1097/JNN.0b013e31826663f2

[4] Smith J, Foster A, Young J. Cochrane review: information provision for stroke patients and their caregivers. Cochrane Group for information provision after a stroke. Clinical Rehabilitation 2009; 23(3): 195-206. John Wiley \& Sons, Ltd. PMid:19218295 http://dx.doi.org/10.1177/0269215508092820

[5] Mattila E, 2011. Aikuispotilaan ja perheenjäsenen emotionaalinen ja tiedollinen tuki sairaalahoidon aikana (Emotional and Informational Support for an Adult Patient and their Family During Hospitalization). Tampere. Acta Universitatis Tamperensis, 16-46. University of Tampere. 2011.

[6] Virtanen P, Paavilainen E, Helminen M, Åstedt-Kurki P. Aivoverenkiertohäiriöpotilaan läheisen tiedonsaanti ensiapupoliklinikalla (The Information Availability for the Families of Stroke Patients at an Emergency Ward). Suomen Lääkärilehti (Finnish Medical Journal). 2011; 11: 915-919.

[7] Smith J, Foster A, House A, Knapp P, Young J. Information provision for stroke patients and their caregivers. Cochrane Database of Systematic Reviews[Internet]. 2008; Issue 2. Art. No.: CD001919.DOI:10.1002/14651858.CD001919.pub2. Available from: http://onlinelibrary.wiley.com/doi/10.1002/14651858.CD001919.pub2/abstract http://dx.doi.org/10.1002/14651858.CD001919.pub2

[8] Yedidia MJ, Tiedemann A. How do family caregivers describe their needs for professional help? American Journal of Nursing 2009; 108(9): 35-38.

[9] Burns N, Grove SK. The practice of nursing research. Appraisal, synthesis, and generation of evidence, sixth Edition. St Louis. Saunders/Elsevier. 2009.

[10] Käypä hoito (Current Care Guidelines). Aivoinfarkti (Strokes)[Internet]. 2011[cited 2012 January]. Available from http://www.kaypahoito.fi/web/kh/suositukset/naytaartikkeli/tunnus/hoi50051

[11] Jumisko E, Lexell J, Söderberg S. Living with moderate or severe traumatic brain injury. The meaning of family members' experiences. Journal of Family Nursing. 2007; 13 (3): 353-369. http://dx.doi.org/10.1177/1074840707303842

[12] Polit DF, Beck CT. Nursing research. Generating and assessing evidence for Nursing practice, ninth Edition. Philadelphia. Lippincott Williams \& Wilkins; 2012.

[13] Ekwall A, Gerdtz M, Manias E. The influence of patient acuity on satisfaction with emergency care: perspective of family, friends and carers. Journal of Clinical Nursing. 2008; 17: 800-809. http://dx.doi.org/10.1111/j.1365-2702.2007.02052.x

[14] Hiidenhovi H. Palvelumittarin kehittäminen sairaalan poliklinikalla. (Developing a Service Measure at an Emergency Ward). Tampere. Acta Universitatis Tamperensis ser A vol 125. Tampereen yliopisto. 2001.

[15] Lehto B, Kylmä J, Åstedt-Kurki P. The everyday life of adult family members of working aged survivors of stroke during the first year after the stroke - an integrative review. Clinical Nursing Studies. 2013; 1(3): 7-18. http://dx.doi.org/10.5430/cns.v1n3p7

[16] Söderström I-M, Benzein E, Saveman B-I. Nurses' experiences of interactions with family members in intensive care units. Scandinavian Journal of Caring Sciences 2003; 17 (2): 185-192. http://dx.doi.org/10.1046/j.1471-6712.2003.00222.x

[17] Hickman L, Newton P, Halcomb E, Chang E, Davidson P. Best practice interventions to improve the management of older people in acute care settings: a literature review. Journal of Advanced Nursing. 2007; 60: 113-126.

PMid:17877559 http://dx.doi.org/10.1111/j.1365-2648.2007.04417.x

Published by Sciedu Press 
[18] Lutz BJ, Young ME. Rethinking intervention strategies in stroke family caregiving. Rehabilitation Nursing 2010; 35(4): 152-160. http://dx.doi.org/10.1002/j.2048-7940.2010.tb00041.x

[19] Rodgers H, Bond S, Curless R. Inadequacies in the provision of information to stroke patients and their families. Age and Ageing 2001; 30: 129-133. http://dx.doi.org/10.1093/ageing/30.2.129

[20] Glimelius B, Birgegård G, Hoffman K, Kvale G, Sjödén P-O. Information and communication with patients: improvements and psychosocial correlates in a comprehensive care program for patients and their relatives. Patient Education and Counselling 1995; 25: 171-182. http://dx.doi.org/10.1016/0738-3991(94)00655-6

[21] Craig P, Dieppe P, Macintyre S, Michie S, Nazareth I, Petticrew M. Developing end evaluating council guidance. British Medical Journal. 2008; 29(337): 1-39.

[22] Hoffmann T, McKenna K. Analysis of stroke patients' and carers' reading ability and the content and design of written materials: Recommendations for improving written stroke information. Patient Education and Counseling 2006; 60: $286-293$. PMid:16098708 http://dx.doi.org/10.1016/j.pec.2005.06.020

[23] Brereton L, Nolan M. 'Seeking': a key activity for new family carers of stroke survivors. Journal of Clinical Nursing 2002; 11: 22-31. http://dx.doi.org/10.1046/j.1365-2702.2002.00564.x

[24] Saveman B-I. Family Nursing Research for Practice: The Swedish perspective. Journal of Family Nursing. 2010; 16(1): 26-24. PMid:20145285 http://dx.doi.org/10.1177/1074840709360314

[25] Paavilainen E, Salminen-Tuomaala M, Kurikka S, Paussu P. Experiences of counselling in the emergency depatrment during the waiting period: importance of family participation. Journal of Clinical Nursing. 2009; 18(15): 2217-2224.

PMid:19583653 http://dx.doi.org/10.1111/j.1365-2702.2008.02574.x 